\title{
Combined thermal manikin and thermal model predictions of working times in fully encapsulated impermeable suits
}

\author{
Emiel A DenHartog ${ }^{*}$, A Shawn Deaton \\ From 15th International Conference on Environmental Ergonomics (ICEE XV) \\ Portsmouth, UK. 28 June - 3 July 2015
}

\begin{abstract}
Introduction
This project aimed to develop guidelines for safe working times in fully encapsulated impermeable suits and incorporate these data into an existing Chemical Companion Decision Support System (CCDSS) that is used by First responders in the US and abroad. The CCDSS provides guidelines on many operational aspects of response to a hazardous materials (HazMat). This study addresses the use of a thermos-physiological model, combined with a sweating thermal manikin, to simulate the data and compared that to the experimental data.
\end{abstract}

\section{Methods}

Using 17 local male firefighters in an age range of 25 to 50 , six commercially available suits were used, in combination with the self-contained breathing apparatus (SCBA). Three climates were evaluated in experiments lasting maximally 60 minutes: moderate $\left(20^{\circ} \mathrm{C}\right.$ WBGT), warm $\left(30^{\circ} \mathrm{C}\right.$ WBGT $)$ and hot $\left(37^{\circ} \mathrm{C}\right.$ WBGT $)$ at a moderate work load $\left(229 \mathrm{~W} \cdot \mathrm{m}^{-2}\right)$. Additionally, 2 workloads (low, $164 \mathrm{~W} \cdot \mathrm{m}^{-2}$ and high, $283 \mathrm{~W} \cdot \mathrm{m}^{-2}$ ) were evaluated in the moderate climate. Measurements included gastrointestinal (GI) temperature 4 local skin temperatures (ISO9886), body mass loss, heart rate and comfort scores. In total 163 tests were performed with 45 different subjects. In addition the suits were evaluated on a standard Sweating Thermal Manikin to which Thermoanalytics' RadTherm model was linked to simulate the thermo-physiological response to the manikin's heat loss. The model outputs are the predicted core temperature, skin temperature and sweat rate over time; and the model also has the possibility to show differences

\footnotetext{
* Correspondence: eadenhar@ncsu.edu

Thermal Protection and Comfort Center (TPACC), College of Textiles, North
} Carolina State University, Raleigh, NC, USA

(c) 2015 DenHartog and Deaton; This is an Open Access article distributed under the terms of the Creative Commons Attribution License (http://creativecommons.org/licenses/by/4.0), which permits unrestricted use, distribution, and reproduction in any medium, provided the original work is properly cited. The Creative Commons Public Domain Dedication waiver (http://creativecommons.org/ publicdomain/zero/1.0/) applies to the data made available in this article, unless otherwise stated.

\section{Discussion and conclusion}

The temperature measured by the pill most closely reflects a rectal temperature which has shown to be lagging compared to central temperature. In the latest version the Thermoanalytics model intends to predict both Hypothalamus, reflecting central temperature and rectal temperature. The data presented here suggested that the actual measured data had a faster response than the rectal temperature simulation. As insufficient data was available on the exact calculation of the thermal inertia and the local heat and mass transfer through the blood flow, it was inconclusive if the model was under-predicting the thermal response or the actual pill temperature exhibited a 
true middle value between rectal and hypothalamus temperature. For prediction of safe working times, based on estimated climate and work loads, the Thermophysiological model linked to the thermal manikin may be very helpful, but further improvements to the time lags as measured rectal and by the temperature pill may be needed.

\section{Acknowledgements}

This project was funded by the US Department of Defense, executed in collaboration with the Netherlands Organization for Applied Scientific Research (TNO).

Published: 14 September 2015

- Convenient online submission

- Thorough peer review

- No space constraints or color figure charges

- Immediate publication on acceptance

- Inclusion in PubMed, CAS, Scopus and Google Scholar

- Research which is freely available for redistribution 